\title{
International Comparisons of Corporate Social Responsibility
}

\author{
Pimentel LV', Branca AS $^{2}$ and Catalão-Lopes $\mathbf{M}^{2 *}$
}

${ }^{1}$ Instituto Superior Técnico, Universidade de Lisboa, Portugal

${ }^{2}$ Centre for Management Studies of Instituto Superior Técnico (CEG-IST), Instituto Superior Técnico, Universidade de Lisboa, Portugal

\begin{abstract}
Competition among firms has led to a broader view of the business' role in society, going beyond mere economic and legal factors and including also social aspects. Consumers value more the social and environmental performance of companies. However, Corporate Social Responsibility (CSR) practices are not receiving equal attention in all countries nor they are embodied the same way. In this context it becomes interesting to evaluate in which countries CSR culture is more ingrained and consolidated. In this paper a score is computed enabling to characterize CSR in different countries. The results show that, among the selected economies (USA, France, Norway and Italy), Norway presents the highest CSR figure and USA the lowest. Countries with the highest CSR values seem to present the least social inequalities. Overall the study is a step forward for understanding how CSR practices are being incorporated and developed in different countries, as they create value for both the companies and the societies.
\end{abstract}

Keywords: Corporate Social Responsibility; International Comparisons; CSR Indexes; Robustness; Macroeconomic conditions and CSR

\section{Introduction}

In recent years, particularly in the last decade, a sharp increase in the study of Corporate Social Responsibility (CSR) can be noticed. In fact, nowadays companies are increasingly encouraged to act in a socially responsible way. This behavior undergoes a greater coverage of the role of business in society, beyond profit maximization and wealth creation.

It is easy to understand the importance of CSR in the context of society and stakeholders such as employees, customers, suppliers and others. However, the relevance of this topic goes beyond the welfare of society, since it can also be seen as a differentiating factor. Consumers are looking for products and practices that provide the greatest benefit to the environment and to society in general, recognizing companies that act with social responsibility and turning this into a competitive advantage. Due to competition between companies and pressure of governments, there has been an increasing attention to CSR as a way of trying to achieve that competitive advantage. A well-incorporated social responsibility culture in the values of a company gives a competitive advantage over competitors and also provides greater welfare to the community as well as a possible reduction of government expenditure.

To better understand the concept of CSR it is important to understand all the dimensions that surround it. According to Dahlsrud [1], Caroll was not only the most famous author on this topic, but also the one whose theory was widely accepted, and probably the most valuable on the actual content of corporate social responsibility. Carroll [2] considered that a definition of social responsibility covering all the obligations a company owes to society should incorporate economic, legal, ethical and philanthropic factors of corporate performance. In 1991, the author joined his theory into four types, defining the pyramid of corporate social responsibility as shown in Figure 1. First, the economic responsibility is the base of the pyramid, meaning that profitability is the prerequisite condition underpinning the development of the remaining ones. The second level of the pyramid is the legal responsibility, since companies must pursue profits always within the Law. Legal responsibility requires companies to comply with the Law and act according to the rules. The next level is the ethical responsibility that encompasses all activities or practices that reflect what is just and fair, even when companies are not required to perform them in the legal framework. Finally, at the top of the pyramid there is the philanthropic responsibility of business, which encompasses all business matters taken in order to improve the quality of life of the employees, the local communities and the society in general. This last level of the Carroll's pyramid addresses a wide range of CSR issues, such as charitable donations, support to local schools, or sponsoring art and sporting events, among others [3,4].

This paper studies the differences in CSR behavior among some economies. Given that this subject has not received the same attention in all countries or at all times, the main goal is to provide a sense of overview of the state of CSR in each of the countries studied. The selected countries are the USA, Norway, France and Italy, since they represent different cultures: North America, Nordic countries, Central Europe and Mediterranean countries. Also, these countries exhibit differences regarding the role of the government and of companies in deploying CSR: in the United States and in Norway, there is a higher reliance on companies to have a social responsibility, in other European countries such as Italy and France, it is expected that the government with its policies accomplishes this social role and encourages firms to act in a more socially responsible way. There are differences, nevertheless, between Italy and France: while in Italy, a multi-stakeholder approach is favored to increasingly incentive Italian companies to include these social concerns in their strategies, in France it is mostly accepted that the government has the responsibility over the social welfare [5-7].

To this end, the current paper intends to set a score that reflects the level of social responsibility practiced by companies in each of the four countries studied, as a way of being able to compare these efforts analytically. A measure of standardization (in this case the Gross Domestic Product, GDP, or population) shall be considered, as a way to achieve comparable results. The robustness of the ranking obtained is tested through some variations in the score formula. The relationship with the countries' macroeconomic context is also addressed. In short, this paper aims to characterize the social realities and concerns of companies in countries representing different social realities and also

${ }^{*}$ Corresponding author: Catalao LM, Centre for Management Studies of Instituto Superior Técnico, Instituto Superior Técnico, Universidade de Lisboa, Portugal, Tel+351218418177; E-mail: mcatalao@tecnico.ulisboa.pt

Received March 07, 2015; Accepted March 15, 2016; Published March 18, 2016

Citation: Pimentel LV, Branca AS, Catalão-Lopes M (2016) International Comparisons of Corporate Social Responsibility. Int J Econ Manag Sci 5: 327 doi:10.4172/2162-6359.1000327

Copyright: ( 2016 Pimentel LV, et al. This is an open-access article distributed under the terms of the Creative Commons Attribution License, which permits unrestricted use, distribution, and reproduction in any medium, provided the original author and source are credited. 


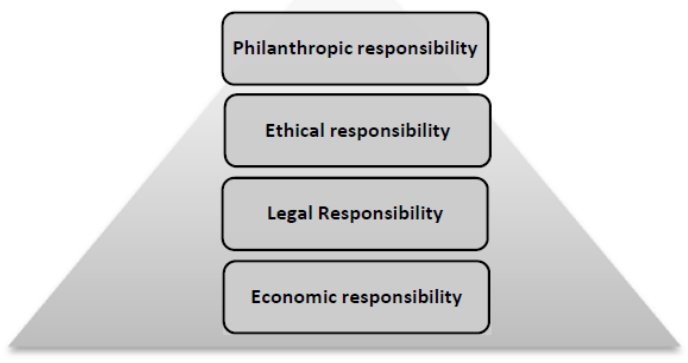

Figure 1: Pyramid of CSR [3].

to understand how CSR relates to the macroeconomic indicators of each country.

\section{Materials and Methods}

CSR is compared in the following four countries: USA, France, Norway and Italy. These countries are chosen because, in addition to data accessibility, they represent North America, Central Europe, the Nordic countries and the Mediterranean countries, and different views regarding the role of the public and the private sector in deploying CSR.

A score is calculated based on the main indexes that assess social responsibility of a country's companies. This score and the indexes included follow the work of Gjølberg [8]. To be considered, an index had to report some aspect of CSR and to be composed of at least 100 companies. In particular, preference was given to those indexes that assume a triple bottom line approach. In order to assess a temporal evolution, two years were considered: 2007 and 2013.

There are seven indexes that meet the above criteria, which we can categorize as measuring:

- Socially responsible investing:

$>\quad$ Dow Jones Sustainability Index;

$>$ Global 100

- Adherence to communities and initiatives that promote CSR:

$>$ UN Global Compact;

$>$ World Business Council for Sustainable Development (WBCSD).

- $\quad$ Reporting of sustainability practices:

> Global Reporting Initiative (GRI);

> Sustain Ability's list of the 100 best sustainability reports.

- $\quad$ Process of accreditation in social responsibility norms

$>$ ISO 14001 .

The number of firms per index and per country is reported in Table 1.

Once all data relating to these indexes $(\mathrm{i}=1 \ldots 7)$ is gathered, the value of CSR in each country $(j=1 \ldots 4)$ is computed using the following expression [8].

$$
\text { value of } \mathrm{CSR}_{j}=\sum_{i=1}^{7} \frac{\left(\frac{\text { Total number of companies from country } j \text { in index } i}{\text { Total number of companies from all countries in index } i}\right)}{\left(\frac{\text { Country } j \text { GDP }}{\text { SUM of the GDP from all countries }}\right)}
$$

Some variations to expression (1) are additionally considered. The
CSR score is calculated using the complete set of all seven indexes, as well as only considering indexes belonging to the following groups: 1) indexes with hard requirements; 2) result-oriented indexes with hard requirements; 3 ) process oriented indexes with hard requirements; 4) indexes with soft requirements. Hard vs. soft requirements correspond to the level of requests and conditions that companies have to meet to be included in the index, representing 'hard requirements' more strict and demanding entry conditions. Result or process-oriented indexes relate to the object of the index, aiming at the measurement of the outcome CSR or of the process conducive to CSR initiatives. As a standardization variable, population will also be essayed in the denominator, besides GDP. We intend to check if the obtained values for CSR exhibit significant variations with these changes, to assess the robustness of the index and of the country ranking obtained. The sources employed for the macroeconomic variables are the World Bank, OECD and Eurostat.

\section{Results Analysis}

Table 2 and Figure 2 represent the results obtained employing expression (1).

Norway is clearly the country that stands out in terms of CSR, despite a 35\% decrease recorded from 2007 to 2013. The remaining countries present similar CSR values in the two years under analysis, with France and the USA showing increases of $9 \%$ and $6 \%$ respectively, and Italy a decline of $7 \%$. In 2007 , Norway almost doubles the score

\begin{tabular}{|l|c|c|c|c|c|c|c|c|}
\hline & \multicolumn{2}{|c|}{ USA } & \multicolumn{2}{c|}{ France } & \multicolumn{2}{c|}{ Norway } & \multicolumn{2}{c|}{ Italy } \\
\cline { 2 - 9 } & $\mathbf{2 0 0 7}$ & $\mathbf{2 0 1 3}$ & $\mathbf{2 0 0 7}$ & $\mathbf{2 0 1 3}$ & $\mathbf{2 0 0 7}$ & $\mathbf{2 0 1 3}$ & $\mathbf{2 0 0 7}$ & $\mathbf{2 0 1 3}$ \\
\hline DJSI World Index & 58 & 75 & 19 & 19 & 5 & 2 & 6 & 6 \\
\hline Global 100 & 17 & 10 & 2 & 9 & 2 & 4 & 0 & 0 \\
\hline UN Global Compact & 128 & 251 & 260 & 972 & 18 & 89 & 87 & 206 \\
\hline WBCSD & 38 & 35 & 9 & 11 & 8 & 5 & 4 & 3 \\
\hline GRI & 201 & 621 & 93 & 71 & 16 & 26 & 67 & 90 \\
\hline Sustainability & 12 & 49 & 8 & 5 & 3 & 0 & 2 & 0 \\
\hline ISO 14001 & 5462 & 5699 & 3476 & 7975 & 618 & 824 & 12057 & 19705 \\
\hline
\end{tabular}

Table 1: Number of firms in each index, per country.

\begin{tabular}{|l|l|l|l|l|}
\hline Year & USA & France & Norway & Italy \\
\hline 2007 & 4,96 & 12,68 & 24,94 & 10,15 \\
\hline 2013 & 5,25 & 13,88 & 16,19 & 9,46 \\
\hline
\end{tabular}

Table 2: Values of CSR (expression 1).

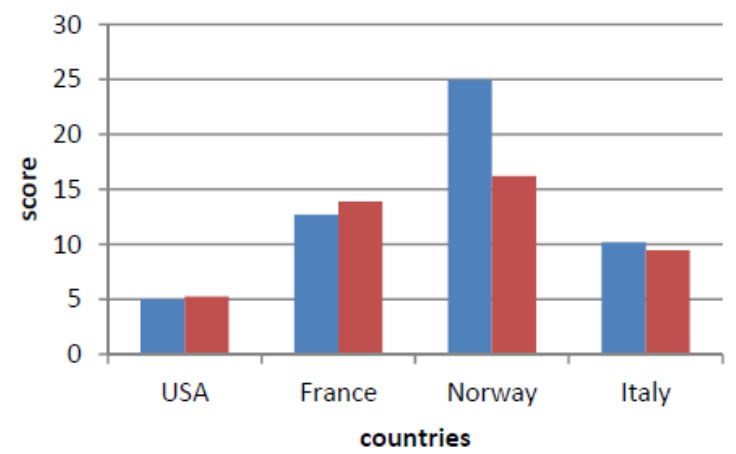

Figure 2: CSR in the four countries studied in 2007 and 2013 (expression 1). 
of the second-placed France, and stands almost five times above the figures for the USA (the last position). In 2013 the countries' ranking is maintained, with Norway in the lead, followed by France, Italy and the USA. However, the almost $10 \%$ growth of France, together with the 35\% decrease of Norway makes the 2013 figures of CSR closer than those of 2007.

\section{Variations to the denominator}

To test the robustness of Gjølberg's formula and to understand whether the ranking is maintained when one of its attributes is changed, a variation to expression (1) was introduced, using population instead of GDP in the denominator.

$$
\text { value of } \operatorname{CSR}_{j}=\sum_{i=1}^{7} \frac{\left(\frac{\text { Total number of companies from country } j \text { in index } i}{\text { Total number of companies from all countries in index } i}\right)}{\left(\frac{\text { Country } j \text { population }}{\text { SUM of the populations from all countries }}\right)}
$$

Figure 3 shows the results obtained.

Qualitative conclusions remain unchanged. From 2007 to 2013 the figure for Norway decreases $26 \%$, the one for Italy decreases $18 \%$, and those for France and the U.S. rise respectively by $3 \%$ and $8 \%$. The correlation coefficient computed between the scores with the two denominators returned 0.966 for 2007 and 0.810 for 2013, thus validating the robustness of the formula to this change.

\section{Variations to the numerator}

To further test the robustness of the country ranking, the number of companies considered was restricted by taking into account the type of requirements for inclusion in the indexes. The exercise was done using expressions (1) and (2). These changes in the numerator shall cause some modifications in the overall index. The smaller these changes are, the more robust is the final index.

Table 3 groups the indexes employed according to requirements and orientation.

If only hard requirements indexes are considered, the country ranking is preserved, independently of using GDP or population in the denominator as shown in Figures $4 \mathrm{a}$ and $4 \mathrm{~b}$. By restricting to hard requirements and result oriented indexes, Italy changes position with the USA and moves to the fourth position as shown in Figures $5 \mathrm{a}$ and 5 b. However, hard requirements and process oriented indexes place Italy in the second position, after Norway and followed by France and the USA as shown in Figures $6 \mathrm{a}$ and $6 \mathrm{~b}$. This is true independently of the denominator (GDP or population) and of the year considered (2007 or 2013). If only soft requirements indexes are considered, France shows the best performance when GDP is used in the denominator as shown in Figures $7 \mathrm{a}$ and $7 \mathrm{~b}$.

\section{Index correlation with some macroeconomic variables}

In this section the whole set of indexes is considered to try to infer a relationship between CSR performance and some macroeconomic indicators.

\section{Gini inequality}

To analyze how social inequalities affect CSR in a given country, we resorted to the Gini coefficient. It can be speculated that countries with higher social inequalities are associated with lower efforts of CSR. The Gini coefficient is a measure of inequality that ranges between 0 and 1 , where 0 corresponds to perfect equality in income among the population and 1 is maximum inequality. Looking at the data in Table
4 we observe that Norway has the lowest Gini coefficient and so is the one with less social inequality. France follows and then Italy and the USA respectively, which is precisely the same order of the CSR index that we calculated for 2007 and 2013. Social inequalities thus seem to be highly inversely correlated with CSR.

\section{Unemployment rate}

Unemployment rates by country are shown in Table 5. Norway, the country's most highly-rated in terms of CSR, is also the one with the lowest unemployment rate. However this country is followed by the U.S., which is the country (among the four analyzed) that shows the lowest CSR value. Computations show that there exists a moderate negative correlation between unemployment and the CSR performance of a country. According to some authors [9] when unemployment is high the social responsibility of firms is mostly focused on sustaining production and keeping the jobs. This view is consistent with our findings.

\section{Discussion and Concluding Remarks}

This study compared CSR in four countries representing different social realities. Based on Gjølberg's work [8], we presented an analytical score for global CSR per country, using international renowned rankings already present in the literature. Variations of the formula were tried to test for the robustness of the ranking obtained. The choice of the countries studied followed the literature and the different realities regarding CSR in each of these countries.

If we use the explicit/implicit distinction by Porter \& Kramer [10], in which implicit CSR is defined as a reaction to the corporations institutional environment, while explicit CSR is the result of a voluntary decision of the corporation, the USA are characterized by a more explicit approach to CSR, while Europe is better defined with an implicit approach [5]. But it is considered also that in Europe, companies increasingly assume responsibility for fulfilling stakeholder expectations rather than relying on welfare state institutions, giving a rise to explicit CSR [5]. This may explain the difference in the results obtained from USA and the European countries that were analyzed. Nevertheless, as Matten and Moon [5] conclude, it is still open to future research whether explicit or implicit CSR approaches deal better with different social issues.

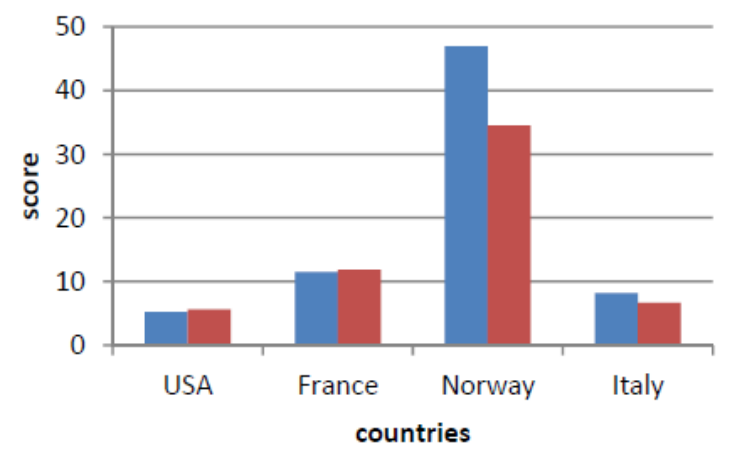

Figure 3: CSR in the four countries studied in 2007 and 2013 (expression 2)

\begin{tabular}{|l|l|l|}
\hline & Hard Requirements & Soft Requirements \\
\hline Result Oriented & DJSI Global 100 Sustainability & \\
\hline Process Oriented & WBCSD ISO 14000 & UN Global Compact GRI \\
\hline
\end{tabular}

Table 3: Index classification according to requirements and orientation. 


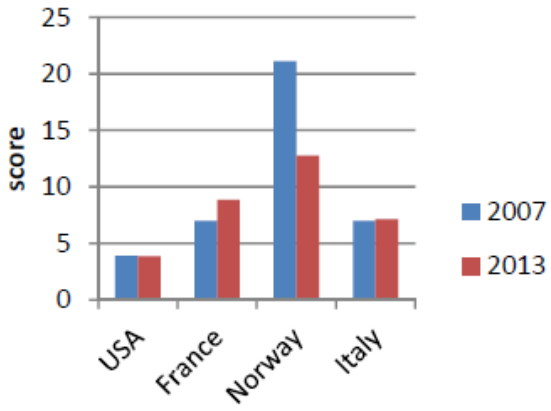

countries

Figure 4a: Hard requirements, GDP.

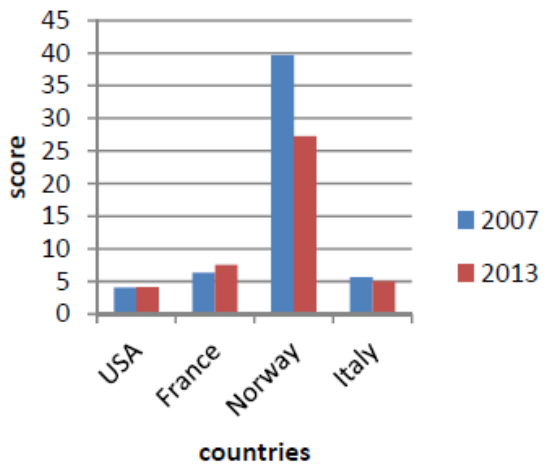

Figure 4b: Hard requirements, population.

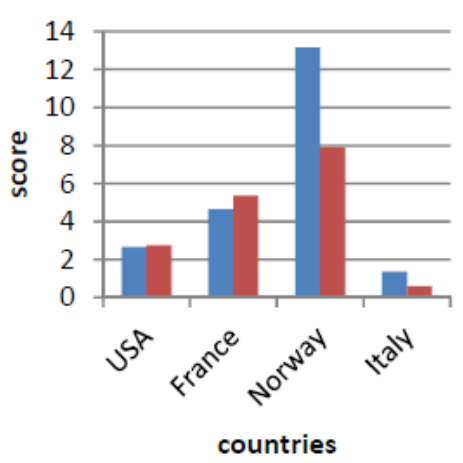

Figure 5a: Hard requirements, result oriented, GDP.

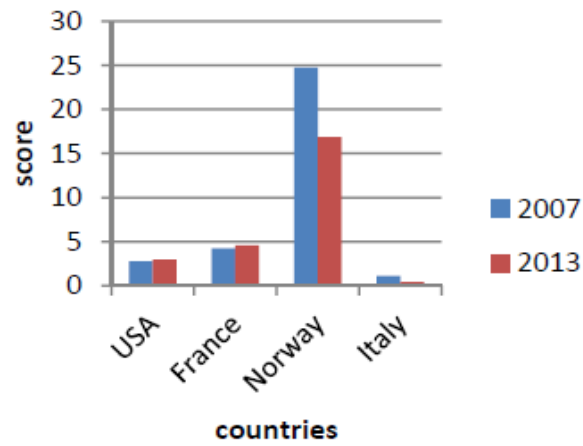

Figure 5b: Hard requirements, result oriented, Population.

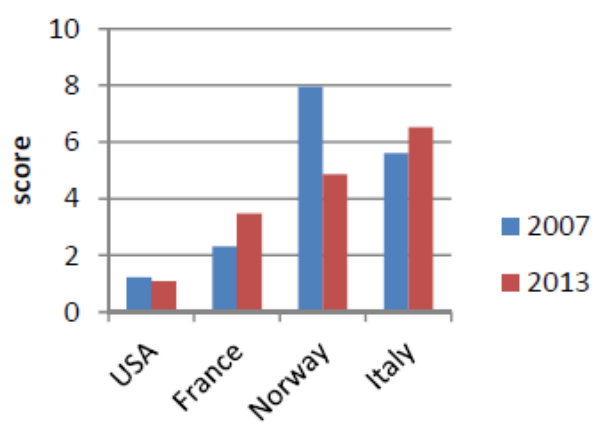

countries

Figure 6a: Hard requirements, process oriented, GDP.

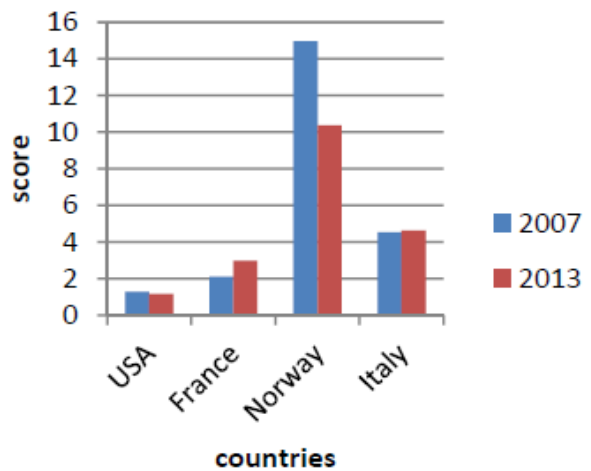

Figure 6b: Hard requirements, process oriented, Population.

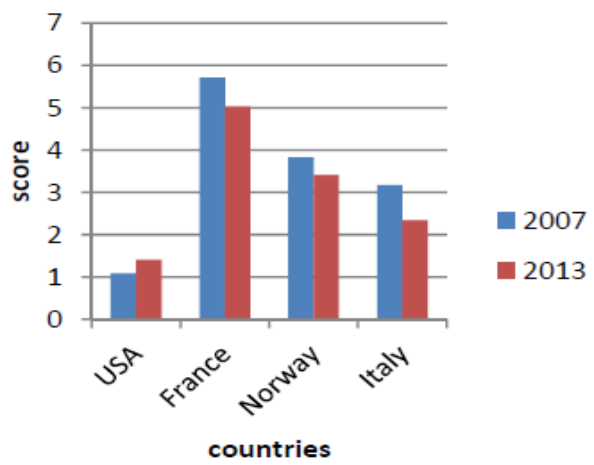

Figure 7a: Soft requirements, GDP.

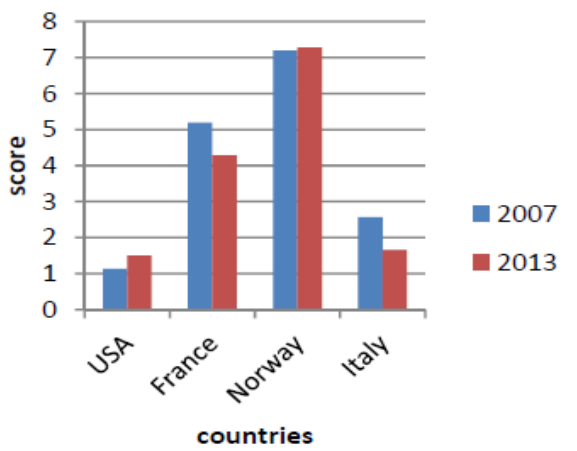

Figure $7 \mathbf{b}$ : Soft requirements, population. 


\begin{tabular}{|c|c|}
\hline Year & $\mathbf{2 0 1 3}$ \\
\hline USA & 0.38 \\
\hline France & 0.29 \\
\hline Norway & 0.25 \\
\hline Italy & 0.34 \\
\hline
\end{tabular}

Table 4: Values of the Gini coefficient for the 4 countries studied.

\begin{tabular}{|c|c|}
\hline Year & $\mathbf{2 0 1 3}$ \\
\hline USA & 7.4 \\
\hline France & 10.3 \\
\hline Norway & 3.5 \\
\hline Italy & 12.1 \\
\hline
\end{tabular}

Table 5: Unemployment rate (\%) in the 4 countries studied.

In the set of European countries that were analyzed, one purpose of the paper was to have diversity and explore the results obtained. This diversity was considered to be attained, as the results mimic different realities in the way CSR is perceived and managed.

For example, Nordic countries, in particular Norway, are considered to be linked to a preference for cooperative agreements and consensus between different types of organizations, largely characterized by the use of partnerships as a tool, and by the creation of a shared area of welfare. Social problems are considered part of governments' core competences with partnership as a strategy to be shared between sectors and actors [11]. Looking at the results obtained, we can see that Norway, with an advanced welfare state built on a resource-based economy, has in the two years analyzed the highest CSR score.

In France, CSR is well-established in government-supported activities focusing on sustainable development. The government has a more regulatory centralized approach, but in recent years the role of companies as increasingly being considered as key in the provision of sustainable development and innovation [11]. While in Italy, as a Mediterranean country, CSR initiatives derived from a consultation process in which governments sought to involve companies and society stakeholders. So, in Italy multi-stakeholder initiatives were developed either business-driven or society-driven, in which the main risk is a possible lack of a systemic approach [12].

These different perspectives and roles of CSR may be used to understand the ranking obtained for the four countries that were studied. Norway, in a more advanced state of CSR policies has the best result, followed by in France and Italy, respectively. The USA has the lowest score, possibly reflecting their more explicit approach to CSR.
Future research could explore the different approaches to CSR in order to shed some light regarding the more effective and efficient way to foster a CSR-minded behavior from the entities involved.

Concerning the relationship between CSR practices and the countries' macroeconomic context, we observed that the Gini coefficient on social inequalities is strongly inversely correlated with CSR, eventually pointing to a corrective role of CSR. Moreover the unemployment rate seems to be inversely correlated with CSR, possibly signing that in times of crisis, when unemployment is growing, companies take care of other priorities, such as keeping profitable and maintaining jobs.

\section{References}

1. Dahlsrud A (2008) How Corporate Social Responsibility is defined: an Analysis of 37 Definitions Corporate Social Responsibility and Environmental Management 15: 1-13.

2. Carroll AB (1979) A Three-Dimensional Conceptual Model of Corporate Performance Academy of Management Review 4: 497-505.

3. Carroll AB (1991) The Pyramid of Corporate Social Responsibility: Toward the Moral Management of Organizational Stakeholders Business Horizons 34: 39-48.

4. Filizöz B, Fişne M (2011) Corporate Social Responsibility: A Study of Striking Corporate Social Responsibility Practices in Sport Management Procedia Social and Behavioral Sciences 24: 1405-1417.

5. Matten D, Moon J (2004) Corporate Social Responsibility Education in Europe Journal of Business Ethics 54: 323-337.

6. Albareda L, Lozano J, Tencati M, Midttun A, Perrini F (2008) The Changing Role of Governments in Corporate Social Responsibility: Drivers and Responses Business Ethics: A European Review 17: 347-363.

7. Nidasio C (2004) Implementing CSR on a large scale: The role of government Paper presented at the 3rd Colloquium of the European Academy of Business in Society, Ghent.

8. Gjolberg M (2009) Measuring the Immeasurable? Scandinavian Journal of Management 25: 10-22.

9. Kemper A, Martin RL (2010) After the fall: the global financial crisis as a test of corporate social responsibility theories European Management Review 7: 229-239.

10. Porter ME, Kramer MR (2006) Strategy \& Society: The Link between Competitive Advantage and Corporate Social Responsibility Harvard Business Review 84: 78-92

11. Albareda L, Lozano J, Ysa T (2007) Public Policies on Corporate Socia Responsibility: The Role of Governments in Europe Journal of Business Ethics 74: 391-407.

12. Albareda L, Tencati L, Lozano J, Perrini F (2006) The Government's Role in Promoting Corporate Responsibility: A Comparative Analysis of Italy and UK from the Relational State Perspective Corporate Governance 6: 386-400. 